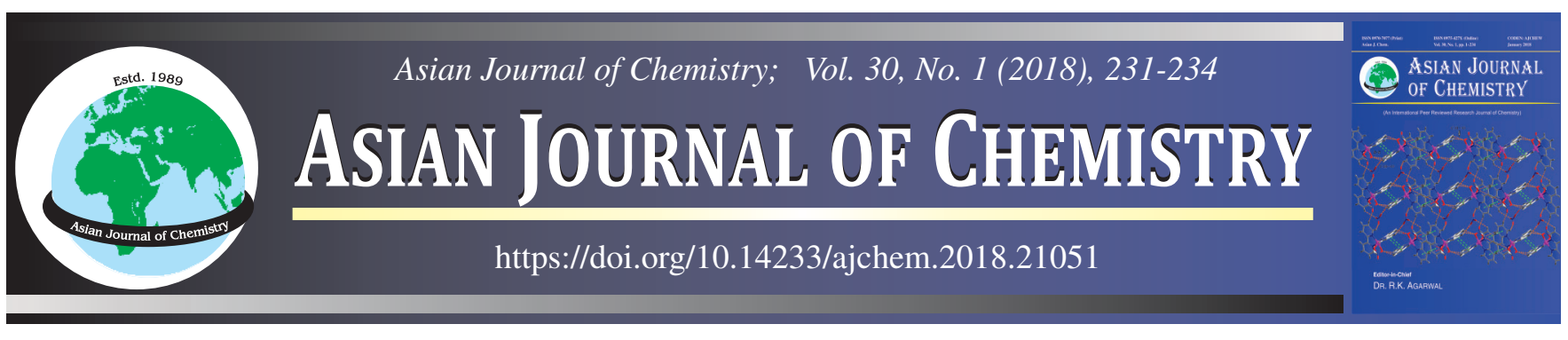

\title{
Characterization, Thermal Degradation, Electrical Conduction and Microbial Activity of Polymer and Its Polymer-Metallic Complexes
}

\author{
S. Gaur ${ }^{*}$, NeElam Jatolia and Vishnu Dutt Mishra
}

Coordination and Bioinorganic Laboratory, Department of Chemistry, Jai Narain Vyas University, Jodhpur-342 001, India

*Corresponding author: E-mail: santwanagaurjnvu@gmail.com

\begin{abstract}
A new polymeric ligand, poly-4-[(pyridine-3-carboimino)]benzene-1,3-diol (P-4-PCIBD) was synthesized via oxidative polycondensation reaction by using sodium hypochloride oxidant in an aqueous alkaline medium at $70{ }^{\circ} \mathrm{C}$. Polymer metal complexes, P-4-PCIBDM(II)] subsequently prepared with $\mathrm{Pb}(\mathrm{II}), \mathrm{Mg}(\mathrm{II}), \mathrm{Ca}(\mathrm{II})$ and $\mathrm{Zn}(\mathrm{II})$ ions. The structures of the synthesized compounds were characterized by IR, $\mathrm{UV},{ }^{1} \mathrm{H}$ and ${ }^{13} \mathrm{C}$ NMR, TGA, elemental analysis and solubility tests. ${ }^{1} \mathrm{H}$ and ${ }^{13} \mathrm{C}$ NMR data shows that the polymerization proceeded through $\mathrm{C}-\mathrm{C}$ coupling of ortho and para positions according to -OH groups of 4-PCIBD. TGA results revealed that all the polymer metal complexes have high thermal stablility than the parental ligand. The conductivities of the polymer-metal complexes were found in the range $10^{-11}-10^{-5} \mathrm{~S} / \mathrm{cm}$.
\end{abstract}

Keywords: Poly-4-[(pyridine-3-carboimino)]benzene-1,3-diol, Oxidative polycondensation.

\section{INTRODUCTION}

Research interest in polyazomethines continues owing to their various characteristics such as chelating properties [1,2] thermal stability $[3,4]$, liquid crystal properties as well as intrinsic conductivity $[5,6]$. A new method of synthesizing polyazomethine was reported i.e. oxidative polycondensation of monomers containing azomethine linkages [7-9]. Phenols and their substituents can be easily polymerized by using oxidants such as $\mathrm{NaOCl}, \mathrm{H}_{2} \mathrm{O}_{2}$ and $\mathrm{O}_{2}$ which are cheap and easily available. This resulted in the formation of polymeric metal complex compounds having useful properties such as catalytic activity, thermal stability, conductivity and antimicrobial properties [10-13]. Aromatic polymers containing ester and azomethine units are of type of high performance polymers with excellent thermal, physical and mechanical properties [14]. Ester group is believed to increase the electrical conductivity of the copolymers [15].

Opto-electronic properties of series of hole-transport materials based on main-chain triphenylamine based poly(azomethines) exhibited high glass transition temperature $\left(\mathrm{T}_{\mathrm{g}}>250^{\circ} \mathrm{C}\right)$ and displayed outstanding thermal stabilities [16]. Similarly, iodinedoped conjugated aromatic poly(azomethine) derivative, poly (3',4'-dibutyl-L-terthiophene-azomethine-1,4 phenyleneazomethine) revealed electrical conductivities of the order of $10^{-7}-10^{-8} \mathrm{~s} / \mathrm{cm}$ [17]. A variation in the backbone ring (fluorene, carbazole or naphthalene) or donor/acceptor side group on the phenylene ring of thiophene based polyazomethines affected the dihedral angles, thus resulted in the variation of electronic properties (ionization potential, electron affinity and band gap, which is very important for electronic or optoelectronic applications of such materials [18].

A new ferrocene-based poly(azomethine) ester obtained by polycondensation exhibited highly antioxidant $\left(\mathrm{IC}_{50}=2.05\right.$ ppm) property and protected the plasmid DNA from damage [19]. A new generation of thermally stable and conducting poly(azomethine) ester revealed a nano-blended morphology for the melt-blended system owing to increased physical interactions (hydrogen bonding and $\pi-\pi$ stacking) between the constituent polymers, making it a efficient opto-electronic device [20].

More functional oligophenols may be used to clean toxic heavy metals in industrial waste waters also. In addition, Schiff base compounds have been used for the determination of transition metals in some natural food samples [21]. Therefore, an impetus to synthesize such compounds was developed which has a great importance in analytical, environmental and food chemistry.

\section{EXPERIMENTAL}

All the materials were of analytical grade and used as such. Elemental analysis was carried out with standard procedures [22]. The ultraviolet visible spectra were measured by a Perkin 
Elmer Lambda UV Chemito Spectroscan UV 2600. The infrared spectra were measured by a Perkin Elmer FT-IR spectrum one (4000-550 $\mathrm{cm}^{-1}$ ). ${ }^{1} \mathrm{H}$ and ${ }^{13} \mathrm{C}$ NMR spectra (Bruker Avance DPX400 and $100.6 \mathrm{MHz}$, respectively) were recorded at $25^{\circ} \mathrm{C}$ by using deuterated DMSO as a solvent. TMS was used as internal standard. Thermal data were obtained by using Perkin Elmer Diamond Thermal analyzer TGA-4000. Measurements were made between $20-1000{ }^{\circ} \mathrm{C}$ (in $\mathrm{N}_{2}$ atmosphere, rate $10^{\circ} \mathrm{C} / \mathrm{min}$ ). Conductivity was measured on a Keith Conductivity Bridege 305 . The pellets were pressed on a hydraulic press developing up to $1687.2 \mathrm{~kg} / \mathrm{cm}^{2}$. Iodine doping was carried out by exposure of the pellets to iodine vapour at atmospheric pressure and room temperature in a dessicator [23].

Synthesis of 4-[(pyridine-3-carboimino)]benzene-1,3diol (4-PCIBD): 4-[(Pyridine-3-carboimino)]benzene-1,3-diol was prepared by the condensation of 2,4-dihydroxy benzaldehyde ( $1.38 \mathrm{~g}, 0.01 \mathrm{~mol})$ with pyridine-3-carboxamide $(0.98$ $\mathrm{g}, 0.01 \mathrm{~mol})$ in methanol $(25 \mathrm{~mL})$, achieved by heating the solution in microwave conditions. The precipitate was collected, recrystallized from methanol and dried.Yield: $68 \%$. ${ }^{1} \mathrm{H}$ NMR (DMSO); 13.50 (s, 1H, -OH) ; $9.35(\mathrm{~s}, 1 \mathrm{H},-\mathrm{CH}=\mathrm{N}) ; 15.94$ (s, 1H, Ar-Ha); 6.64 (d, 1H, -Hb); 8.61 (d, 1H, -Hc); 6.64 (q, 1H, Ar-Hd); 7.90 (t, 1H, Ar-He); 7.37 (t, 1H, Ar-Hf). ${ }^{13} \mathrm{C}$ NMR (DMSO): $218(\mathrm{C}-\mathrm{C}=\mathrm{O}) ; 150\left(\mathrm{C}_{5} \mathrm{H}_{4} \mathrm{~N}\right) ; 70-100(\mathrm{~N}=\mathrm{C}-\mathrm{H}) ; 142$ $(\mathrm{C}=\mathrm{C}) ; 160-185$ (-C=C-OH).

Synthesis of poly-4-[(pyridine-3-carboimino)]benzene1,3-diol (P-4-PCIBD): P-4-PCIBD was synthesized through oxidative polycondensation of PCIBD with an aqueous solution of $30 \% \mathrm{NaOCl}$ [22]. PCIBD $(0.138 \mathrm{~g}, 0.001 \mathrm{~mol})$ was dissolved in an aqueous solution of $\mathrm{KOH}(10 \%, 0.001$ $\mathrm{mol}$ ) and placed into a $50 \mathrm{~mL}$ of three-necked round-bottom flask. It was fitted with a condenser, thermometer, stirrer and an additional funnel containing $\mathrm{NaOCl}$. After heating to $40^{\circ} \mathrm{C}$, $\mathrm{NaOCl}$ was added dropwise over about $20 \mathrm{~min}$. The reaction mixture was cooled to room temperature and then $0.001 \mathrm{~mol}$ $\mathrm{HCl}(37 \%)$ was added. For the separation of mineral salts and unreacted monomers, the mixture was filtered and washed with hot water $(50 \mathrm{~mL})$ and then dried in oven at $110^{\circ} \mathrm{C} .{ }^{1} \mathrm{H}$ NMR
(DMSO); 13.50 (s, 1H,-OH); 9.35 (s, 1H, -CH=N); 15.94 (s, $1 \mathrm{H}, \mathrm{Ar}-\mathrm{Ha}) ; 6.64$ (d, 1H, Hb); 8.61 (d, 1H, Hc); 6.64 (q, 1H, Ar-Hd).

Synthesis of poly-4-[(pyridine-3-carboimino)]benzene1,3-diol-metal complexes: Solution of $\mathrm{M}(\mathrm{OAc})_{2} \cdot x \mathrm{H}_{2} \mathrm{O}(\mathrm{M}=$ $\mathrm{Mg}, \mathrm{Ca}, \mathrm{Pb}, \mathrm{Zn}) ;(\mathrm{x}=4,1,3,2)$ in methanol (10 mL, $1 \mathrm{mmol})$ was added to a solution of P-4-PCIBD ( $2 \mathrm{mmol} / \mathrm{unit})$ in THF $(20 \mathrm{~mL})$. The mixture was stirred and heated at $70{ }^{\circ} \mathrm{C}$ for $5 \mathrm{~h}$. The precipitated complex was filtered, washed with cold methanol/THF (1:1) and dried in oven at $110^{\circ} \mathrm{C}$ (Table-1).

\section{RESULTS AND DISCUSSION}

Solubility: 4-[(Pyridine-3-carboimino)]benzene-1,3-diol (4-PCIBD) was dark yellow coloured crystalline, completely soluble in methanol, ethanol, acetone, THF, DMF and DMSO, but insoluble in benzene and toluene. Poly-4-[(pyridine-3carboimino)]benzene-1,3-diol (P-4-PCIBD) is a dark brownish grey powder, soluble in THF, DMF and DMSO, insoluble in ethanol, ethyl acetate, benzene and carbon tetrachloride. Polymer-metal complexes were found to be insoluble in all the organic solvents.

UV-visible analysis: UV-visible (methanol and DMSO) of 4-PCIBD revealed $\mathrm{K}$ bands and $\mathrm{R}$ band of phenol at 205 and $178 \mathrm{~nm}$, respectively. K band of 4-PCIBD (pyridine) and $\mathrm{R}$ band of $-\mathrm{CH}=\mathrm{N}$ - groups at 232 and $351 \mathrm{~nm}$ were also visible. However, in case of P-4-PCIBD, K and R bands of phenol were observed at 235 and $355 \mathrm{~nm}$, respectively and at 372 the clear $\mathrm{K}$ band of $-\mathrm{CH}=\mathrm{N}$ group.

Thus the spectra show specific bands at $\lambda_{\max } 280$ and 350 $\mathrm{nm}$ assigned to aromatic $\mathrm{C}=\mathrm{O}$ and azomethine transitions, respectively. The shifting of $\mathrm{CH}=\mathrm{N}$ group band from 351 to $372 \mathrm{~nm}$ has been assigned for the formation of polymeric conjugated $\pi$-system.

FT-IR analysis: In the FT-IR spectra of 4-PCIBD and P4-PCIBD bands of $-\mathrm{OH}$ and $-\mathrm{CH}=\mathrm{N}$ groups were observed at 3254 and $1625 ; 3158$ and $1605 \mathrm{~cm}^{-1}$, respectively. The details of key IR bands of ligand, polymer and polymer-metal complexes are shown in Table- 2 .

TABLE-1

ELEMENTAL ANALYSES DATA AND YIELD OF LIGAND, POLYMER AND POLYMER-METAL COMPLEXES

\begin{tabular}{|c|c|c|c|c|c|c|}
\hline \multirow{2}{*}{ Compound } & \multirow{2}{*}{ Colour } & \multicolumn{4}{|c|}{ Calculated (found) } & \multirow{2}{*}{ Yield (\%) } \\
\hline & & $\mathrm{C}$ & $\mathrm{H}$ & $\mathrm{N}$ & Metal & \\
\hline 4-PCIBD & Dark yellow brown & 64.46 & 4.13 & 11.57 & - & 68 \\
\hline P-4-PCIBD & Dark brownish grey & 64.73 & 3.73 & 11.61 & - & 65 \\
\hline P-4-PCIBD-Pb & Brown & 34.80 & 2.00 & 6.24 & 46.22 & 52 \\
\hline P-4-PCIBD-Mg & Yellowish brown & 58.80 & 3.39 & 10.55 & 9.15 & 65 \\
\hline P-4-PCIBD-Ca & Dark yellow & 55.50 & 3.20 & 9.96 & 14.25 & 60 \\
\hline P-4-PCIBD-Zn & Greyish black & 50.91 & 2.93 & 9.13 & 21.33 & 52 \\
\hline
\end{tabular}

TABLE-2

FT-IR $\left(\mathrm{cm}^{-1}\right)$ DATA OF 4-PCIBD, P-4-PCIBD AND ITS METAL COMPLEXES

\begin{tabular}{|c|c|c|c|c|c|c|c|}
\hline \multirow{2}{*}{ Compounds } & \multicolumn{7}{|c|}{ Wavenumber $\left(\mathrm{cm}^{-1}\right)$} \\
\hline & $v(-\mathrm{OH})$ & $v(\mathrm{Ar}-\mathrm{C}-\mathrm{H})$ & $v(-\mathrm{CH}=\mathrm{N})$ & $v(-C=C)$ & $v(-\mathrm{C}=\mathrm{O})$ & $\mathrm{v}(\mathrm{M}-\mathrm{O})$ & $v(\mathrm{M}-\mathrm{N})$ \\
\hline 4-PCIBD & 3254 & 3050 & 1625 & 1589 & 1215 & 553 & 672 \\
\hline P-4-PCIBD & 3158 & 3020 & 1605 & 1565 & 1195 & 550 & 670 \\
\hline P-4-PCIBD-Pb & 3230 & 3025 & 1616 & 1570 & 1206 & 551 & 671 \\
\hline P-4-PCIBD-Mg & 3258 & 3060 & 1630 & 1580 & 1214 & 557 & 677 \\
\hline P-4-PCIBD-Ca & 3260 & 3030 & 1615 & 1568 & 1207 & 555 & 675 \\
\hline P-4-PCIBD-Zn & 3272 & 3015 & 1610 & 1560 & 1202 & 552 & 673 \\
\hline P-4-PCIBD-Cd & 3250 & 3045 & 1628 & 1575 & 1220 & 556 & 671 \\
\hline
\end{tabular}


NMR analysis: In ${ }^{1} \mathrm{H}$ NMR, the signals of phenolic -OH and $-\mathrm{CH}=\mathrm{N}$ groups $4-\mathrm{PCIBD}$ and $\mathrm{P}-4-\mathrm{PCIBD}$ were obtained at $13.50 \& 9.30 \mathrm{ppm}$ and $11.55 \& 9.94 \mathrm{ppm}$, respectively. Crosslinking in the polymeric structure is expected in those cases where ortho and para-positions in the corresponding monomeric structure are unsubstituted.

Thermogravimetric analysis: TGA curves and data of monomer, polymer and polymer- metal complex compounds are shown in Fig. 1. The onset temperature, 50 and $58 \%$ weight loss of 4-PCIBD and P-4-PCIBD was determined, respectively. In TGA curve of P-4-PCIBD, a weight loss of $14.5 \%$ in the $50-150{ }^{\circ} \mathrm{C}$ was assigned to the removal of absorbed water. Because of long conjugated band systems, polymer demonstrated higher resistance against high temperature than monomer [24-26].

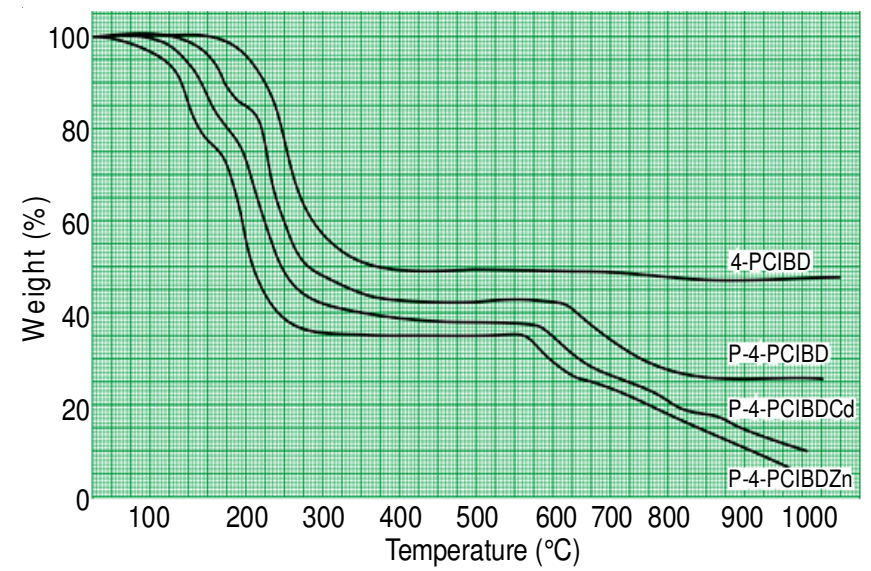

Fig. 1. TGA curves of monomer, polymer and its $\mathrm{Cd}$ and $\mathrm{Zn}$ complexes

P-4-PCIBD-Zn complex demonstrated higher thermal stability as compared to other polymer-metal complex because of smaller size. The high thermal stability of polymer-metal complex compounds indicate the formation of metal-oxygen valence and metal-nitrogen coordination bond between polymer-metal ions. Presence of water can be seen in the polymeric metal complex curves showing between 5 and $20 \mathrm{wt}$. \% losses in $50-200{ }^{\circ} \mathrm{C}$ range and corresponding to the loss of water (50$\left.150^{\circ} \mathrm{C}\right)$.

Electrical properties of polymer and polymer-metal complexes: Polymer P-4-PCIBD and its metal complexes have conductivities in the range $10^{-11}-10^{5} \mathrm{~S} / \mathrm{cm}$. When doped with iodine, the conductivity increased in magnitude $\left(10^{-5} \mathrm{~S} / \mathrm{cm}\right)$. Little difference in doping effect for the polymer and its metal complexes at various times at $25^{\circ} \mathrm{C}$ was observed. In doping of polymer with iodine, it was observed that the conductivity of polymer and its metal complexes first increases greatly with doping time, but then tends to level off. The highest conductivity was observed in the case of lead compound. The values indicate that a charge-transfer complex between 4-PCIBD and P-4-PCIBD and dopant iodine is continuously formed. Simultaneously, values reflect how fast the doping reaction takes place, but longer doping time is needed to obtain the maximum value. Thus a variation in curve is observed with doping conditions (Fig. 2). Nitrogen being electronegative is capable of coordinating with iodine molecule, this has been also suggested in various literature $[27,28]$.

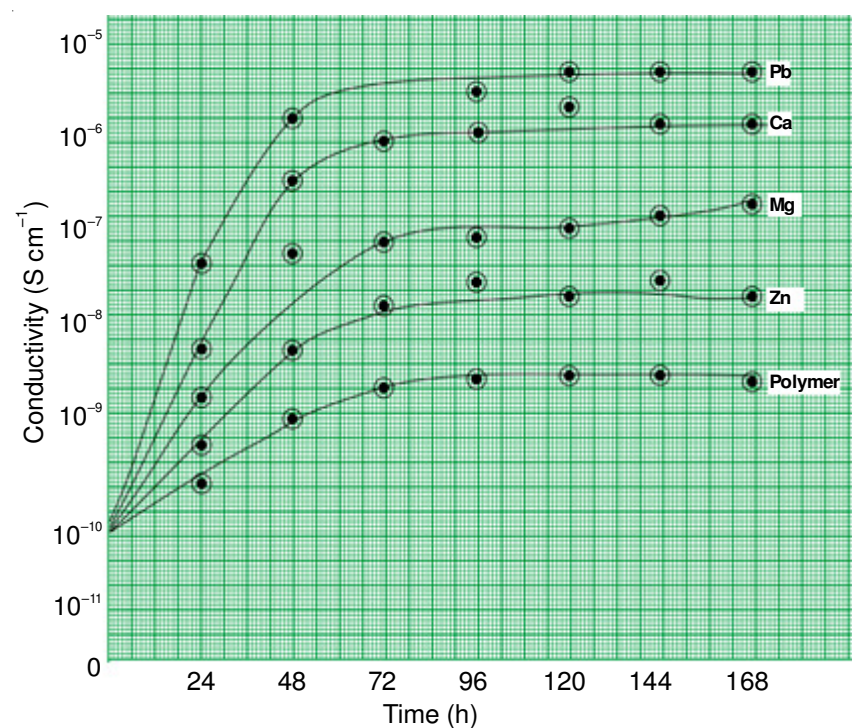

Fig. 2. Electrical conductivity of polymer and its $\mathrm{Pb}, \mathrm{Ca}, \mathrm{Mg}$ and $\mathrm{Zn}-\mathrm{I}_{2}$ doped complex

Microbial activity: The polymer and its metal complexes were dissolved in $50 \mathrm{mg} / \mathrm{mL}$ of acetone. Incubation was done for $24 \mathrm{~h}$ at $37^{\circ} \mathrm{C}$ and inhibition zone around each disc was measured. It is found that polymer P-4-PCIBD exhibited no microbial activity where as the metal coordinated complexes revealed significant activities against $B$. subtilis (Fig. 3).

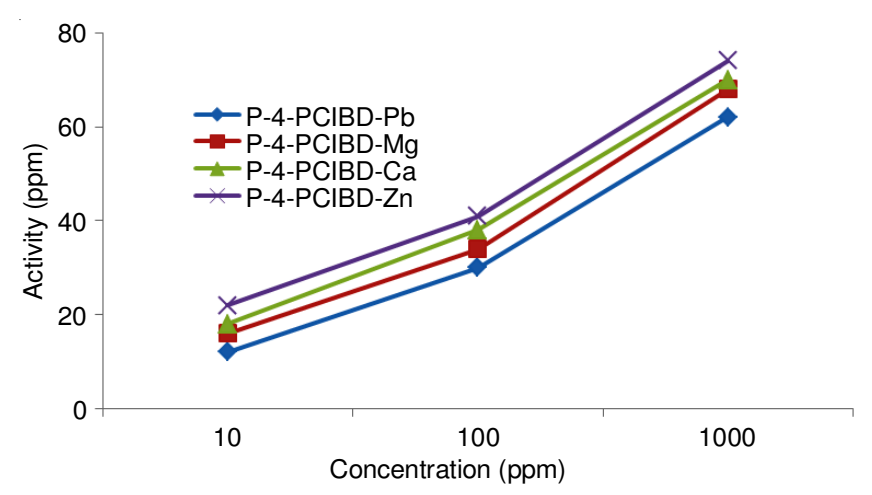

Fig. 3. Antibacterial activity of polymetric metal complexes

\section{REFERENCES}

1. M. Grigoras and N.-C. Antonoaia, Eur. Polym., 41, 1079 (2005); https://doi.org/10.1016/j.eurpolymj.2004.11.019.

2. M. Cazacu, M. Marcu, A. Vlad, A. Tóth and C. Racles, J. Polym. Sci. A Polym. Chem., 41, 3169 (2003); https://doi.org/10.1002/pola.10911.

3. C. Racles, V. Cozan, M. Cazacu, E. Foldes and I. Sajo, High Perform. Polym., 14, 397 (2002);

https://doi.org/10.1177/095400830201400406.

4. U. Shukla, K.V. Rao and A.K. Rakshit, J. Appl. Polym. Sci., 88, 153 (2003); https://doi.org/10.1002/app.11618.

5. A. El-Shekeil and S. Al-Aghbari, Polym. Int., 53, 777 (2004); https://doi.org/10.1002/pi.1450.

6. I. Kaya and M. Gul, J. Euro Polym., 40, 2025 (2004); https://doi.org/10.1016/j.eurpolymj.2004.05.023.

7. I. Kaya and A. Bilici, J. Macromol. Sci. Part A Pure Appl. Chem., 43, 719 (2006); https://doi.org/10.1080/10601320600602688.

8. M. Cazacu, M. Marcu, A. Vlad, G.I. Rusu and M. Avadanei, Organomet. Chem., 689, 3005 (2004); https://doi.org/10.1016/j.jorganchem.2004.05.051. 
9. I. Kaya and A. Bilici, Synth. Met., 156, 736 (2006); https://doi.org/10.1016/j.synthmet.2006.04.008.

10. T. Kaliyappan, A. Raman and P. Kannan, J. Macromol. Sci., Part A, A36, 517 (1999); https://doi.org/10.1081/MA-100101546.

11. D. Ferreira and D. Slade, Nat. Prod. Rep., 19, 517 (2002); https://doi.org/10.1039/b008741f.

12. J.A. Field and G. Lettinga, eds.: R.W. Hemingway and P.E. Laks, Toxicity of Tannic Compounds to Microorganisms, In: Plant Polyphenols. Basic Life Sciences, Springer, Boston, MA, vol. 59 (1992).

13. Z. Yu and R.A. Dahlgren, J. Chem. Ecol., 26, 2119 (2000); https://doi.org/10.1023/A:1005568416040.

14. A. Iwan, M. Palewicz, A. Sikora, J. Chmielowiec, A. Hreniak, G. Pasciak and P. Bilski, Synth. Met., 160, 1856 (2010); https://doi.org/10.1016/j.synthmet.2010.06.029.

15. M. Abdallh, E. Bakir and E. Yousif, J. Saudi Chem. Soc., 18, 387 (2014); https://doi.org/10.1016/j.jscs.2011.08.001.

16. J.C. Hindson, B. Ulgut, R.H. Friend, N.C. Greenham, B. Norder, A. Kotlewski and T.J. Dingemans, J. Mater. Chem., 20, 937 (2010); https://doi.org/10.1039/B919159C.

17. C. Wang, S. Shieh, E. Legoff and M.G. Kanatzidis, Macromolecules, 29, 3147 (1996); https://doi.org/10.1021/ma9514131.

18. F.-C. Tsai, C.-C. Chang, C.-L. Liu, W.-C. Chen and S.A. Jenekhe, Macromolecules, 38, 1958 (2005); https://doi.org/10.1021/ma048112o.
19. A. Gul, Z. Akhter, A. Bhatti, M. Siddiq, A. Khan, H.M. Siddiqe, N.K. Janjua, A. Shaheen, S. Sarfraz and B. Mirza, J. Organomet. Chem., 719, 41 (2012); https://doi.org/10.1016/j.jorganchem.2012.08.010.

20. A. Kausar and S.T. Hussain, Polym. Int., 62, 1442 (2013); https://doi.org/10.1002/pi.4438.

21. A.E. Hagerman, K.M. Riedl, G.A. Jones, K.N. Sovik, N.T. Ritchard, P.W. Hartzfeld and T.L. Riechel, J. Agric. Food Chem., 46, 1887 (1998); https://doi.org/10.1021/jf970975b.

22. G.H. Jeffesry and J. Basett, Vogel's Text Book of Quantitative Inorganic Analysis, Addision-Wesley Boston, USA, edn 6 (1989).

23. G. Euing, Instrumental Method of Chemical Analysis, McGraw Hill Int. ed., New York, edn 5 (1985).

24. F.R. Diaz, J. Moreno, L.H. Tagle, G. East and D. Radic, Synth. Met., 100, 187 (1999); https://doi.org/10.1016/S0379-6779(98)01484-2.

25. H. Sakai, T. Matsuyama, Y. Maeda and H. Yamaoka, J. Chem. Phys., 75, 5155 (1981); https://doi.org/10.1063/1.441864.

26. M. Yildiz, Z. Kilic and J. Hokelek, J. Mol. Struct., 441, 1 (1998); https://doi.org/10.1016/S0022-2860(97)00291-3.

27. F.G. Ehlers, K.R. Fisch and W.R. Powell, J. Poly. Sci., 7, 2931 (1969); https://doi.org/10.1002/pol.1969.150071015.

28. C. Reid and R.S. Mulliken, J. Am. Chem. Soc., 76, 3869 (1954); https://doi.org/10.1021/ja01644a001. 